\title{
Prevalence of anti-sperm antibodies, risk factors associated and their impact on spermatobioscopy in infertile men
}

\author{
Ignacio Aboytes Cardeña ${ }^{1}$, Andrea C. Andrade Rodríguez ${ }^{1}$, \\ Edgar O. Ruiz Treviño ${ }^{2}$, Junior J. Araiza Navarro ${ }^{3 *}$, Enrique R. Muñoz ${ }^{1}$, \\ Armando Roque Sánchez ${ }^{1}$, Patricia A. González ${ }^{1}$
}

\begin{abstract}
${ }^{1}$ Department of Biology of Human Reproduction, National Institute of Perinatology, Mexico City, Mexico ${ }^{2}$ Department of Gynecology and Obstetrics, General Hospital of León, Guanajuato, Mexico

${ }^{3}$ Department of Gynecology and Obstetrics, Naval Medical Center, Mexico City, Mexico
\end{abstract}

Received: 03 February 2019

Accepted: 06 March 2019

\section{*Correspondence:}

Dr. Junior J. Araiza Navarro,

E-mail: joelara16@ hotmail.com

Copyright: (c) the author(s), publisher and licensee Medip Academy. This is an open-access article distributed under the terms of the Creative Commons Attribution Non-Commercial License, which permits unrestricted non-commercial use, distribution, and reproduction in any medium, provided the original work is properly cited.

\section{ABSTRACT}

Background: The first immunological correlation with male infertility was reported in 1954 by Wilson and Rumke with the identification of anti-sperm antibodies. The prevalence of anti-sperm antibodies in infertile men varies from $9 \%-36 \%$, the main cause being the loss of the blood-testicular barrier and otherwise the association with chronic inflammation. It has been shown that immune infertility is found in $15 \%$ of patients with varicocele.

Methods: A transversal comparative study was carried out with 360 infertile men who were tested for anti-sperm antibodies between January 2011 and July 2018. Two groups were integrated; Group 1, infertile men with positive anti-sperm antibodies $>50 \%$, group 2 , infertile men with negative anti-sperm $<50 \%$. Seminogram parameters were evaluated according to the WHO $5^{\text {th }}$ edition and associated risk factors with anti-sperm antibodies.

Results: 360 infertile men were evaluated during the study, 42 were excluded because they did not meet the inclusion criteria, the prevalence of anti-sperm antibodies was $14.5 \%$. Group $1 ; n=46(14.5 \%)$ and group $2, n=272(85.5 \%)$, the clinical characteristics and the hormonal profile were compared at study admission without significant difference. There was a significant decrease in progressive motility in group $1(38.7 \pm 23.8)$ vs group $2(50.1 \pm 18.9) \mathrm{p}=0.03$. Analyzing the risk factors, varicocele was found to be significant $23.7 \%$, OR $2.14(1.27-3.61) \mathrm{p}=0.004$ as well as retractable testicle $26.4 \%$, OR $2.13(1.23-3.70) \mathrm{p}=0.008$.

Conclusions: The affectation of motility was confirmed, which leads to the suspect varicocele and retractable testicle as risk factors.

Keywords: Anti-sperm antibody, Chronic prostatitis, Infection, Inflammation, Male infertility, MAR test, Seminal parameters, Varicocelectomy

\section{INTRODUCTION}

The first immunological correlation with male infertility was reported in 1954 by Wilson and Rumke with the identification of anti-sperm antibodies. ${ }^{1,2}$ The prevalence of anti-sperm antibodies in infertile men varies from $9 \%$ -
$36 \% .^{3}$ The main cause being the loss of the bloodtesticular barrier and the association with chronic inflammation. ${ }^{4}$ Immune infertility has been shown to be found in $15 \%$ of patients with varicocele. ${ }^{5}$ In mammals it is well documented that the presence of anti-sperm antibodies can interfere with fertilization. It has also been 
related to harmful effects on embryonic development and implantation. ${ }^{6,7}$ There is evidence that antibodies can affect sperm binding by affecting the acrosomal reaction altering the binding such as the IZUMO protein and the YLP-12E1 antigen. They are targets of the antibodies and are necessary for said reaction. It is suggested that antisperm antibodies affect fertility producing toxic compounds by inhibiting the synthesis of DNA and the enzyme in the mitochondrial respiratory chain coupled with a decrease in superoxide dismutase, an enzyme responsible for maintaining an oxidant balance, thereby producing oxidative stress and lipid peroxidation damaging the sperm membrane. ${ }^{1}$

The World Health Organization in the $5^{\text {th }}$ edition of its manual (2010) recommends evaluating anti-sperm antibodies by means of two tests, the mixed antiglobulin reaction (MAR) (Figure 1) or the Immunobeads (IB) test, with a cut off value to be considered positive greater than $50 \%$ of mobile sperm with the presence of anti-sperm antibodies. ${ }^{6,8}$

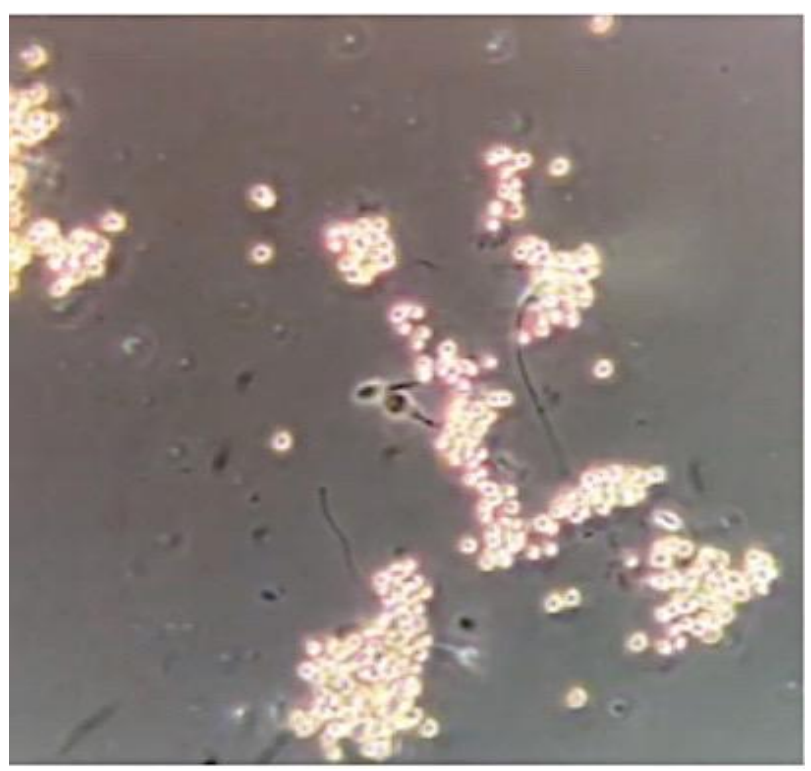

Figure 1: Photograph in phase contrast microscope with 100x objective, observing the mixed antiglobulin reaction test (MAR).

Two types of $\operatorname{IgG}, \operatorname{Ig}$ A antibodies are evaluated and $\operatorname{IgM}$ is rarely found. ${ }^{2}$ The development time of anti-sperm antibodies is not clear, the data of a murine model in which the presence of antibodies after vasectomy was evaluated. suggest that $\operatorname{IgM}$ develops within 2 weeks after injury to the testicular hematogenous barrier; Immunoglobulin $M$ titers subsequently decrease over 4-8 weeks, followed by increasing titers of immunoglobulin $\mathrm{G}$ between 8 to 12 weeks. ${ }^{9}$ In previous reports, the negative effect of anti-sperm antibodies on semen parameters and natural pregnancy has been observed. ${ }^{3}$ In the work of Abshagen et al, 1998, in which fertility was evaluated in 157 infertile couples with an anti-sperm antibody test, different cut-off points were evaluated finding that when there was a $10 \%$ presence of antisperm antibodies the cumulative pregnancy rate during 6 years was high, when they were greater than $10 \%$ but less than $50 \%$ was low and when anti-sperm antibodies were $50-90 \%$ the cumulative pregnancy rate at 6 years was very low. ${ }^{10,11}$ It has been questioned whether anti-sperm antibodies could cause post-fertilization problems that result in clinical pregnancies and result in an increase in the rate of spontaneous abortion. ${ }^{11,12}$ In evaluating this issue, a spontaneous abortion rate of $38 \%$ was found in those males with the presence of anti-sperm antibodies vs $0 \%$ in controls, Check $\mathrm{J}$ et al, 2017 found a spontaneous abortion rate of $14 \%$. $\%$ in those with anti-sperm antibodies $<50 \%$ versus $25 \%$ for those with $>80 \%$ this problem has not been resolved to date. ${ }^{13}$

The objective of the study was to determine the prevalence of anti-spermatozoidetozoid antibodies, the risk factors and their effect on the parameters of spermatobioscopy in males with infertility.

\section{METHODS}

A comparative cross-sectional study was conducted, which included 360 men with infertility who attended the Clinic of Andrology, who underwent an anti-sperm antibody test between January 2011 and July 2018. Two groups were integrated; Group 1, men with infertility and positive anti-sperm antibodies, group 2, men with infertility and negative anti-sperm antibodies.

\section{Inclusion criteria}

- Men with complete seminogram according to WHO criteria (2010); SEA test (mixed antiglobulin reaction) reported as a percentage, male infertility, minimum duration of 12 months, hormonal profile and complete medical history, obtaining information showing history of scrotal surgery, testicular trauma, varicocele, testicular neoplasia, retractable testicle, infections (epididymitis and/or prostatitis).

\section{Exclusion criteria}

- Men with azoospermia or with incomplete information were eliminated.

For the analysis, the data were obtained from the clinical file and from the Andrology laboratory database. A selection of anti-sperm antibodies was made using the mixed antiglobulin reaction test (Ferti SpermMar IgG kit, Fertipro, Belgium). The reading was made in duplicate, a percentage of $50 \%$ of the mobile sperm involved in the mixed agglutination was considered positive for testing. The seminal analysis was obtained through masturbation in a period of abstinence of 3 days and no more than 7 days, all the procedures and interpretations used were subject to the criteria established by the World Health Organization 2010, the evaluation of the morphology of the sperm was performed according to the strict Kruger 
criteria. The analysis included sperm concentration, mobility, morphology and the hypoosmotic swelling test (HOS).

The study variables were sperm concentration, progressive sperm motility, sperm morphology, hypoosmotic swelling test (HOS), leukocytes in semen, luteinizing hormone, follicle stimulating hormone, estradiol, total testosterone, prolactin, thyrotropin, scrotal surgery (antecedent of varicocelectomy and recanalization of the vas deferens), testicular trauma defined as direct contusion in one or both testes, the varicocele was diagnosed using the standard criteria (Jungwirth et al, 2013), including the 3 grades, testicular neoplasia defined as history of testicular cancer in the clinical history, retractable testicle defined as the mobile testicle of the inguinal canal to the scrotal pouch, infections (including epididymitis and/or prostatitis) using the consensus criteria of the National Institutes Health (NIH).

The sample size was calculated to find a prevalence of $15 \%$ positive anti-sperm antibodies with a confidence level of $95 \%$ and an accuracy or error of 5\%. 196 men were required, so it was decided to enter all men in the period of study.

\section{Statistical analysis}

Descriptive statistics were used to characterize both groups, using mean and standard deviation and/or frequency and percentage for quantitative and qualitative variables, respectively. The chi-squared test was performed for the proportional differences and the Student's $\mathrm{T}$ for the differences in the means. $2 \times 2$ contingency tables were performed to calculate the odds ratio (OR), with a confidence interval of $95 \%(95 \% \mathrm{CI})$.

The statistical analysis was performed with the Statistical Package for Social Sciences for Windows program in its version number 24

\section{RESULTS}

During the study period, 360 men with infertility were evaluated, 42 were excluded because they did not meet the inclusion criteria. Therefore, in the present study, 318 infertile men were analyzed with determination of antisperm antibodies. The prevalence of antisperm antibodies was $14.5 \%$. Group 1 included a sample of n:46 (14.5\%) and group 2, n:272 (85.5\%).

Table 1 compared the clinical characteristics and the hormonal profile at study entry, the average age of the male infertile with positive anti-sperm antibodies was: $36 \pm 5.3$ and in males with negative anti-sperm antibodies $36.0 \pm 6.8$ years without significant differences. There were also no significant differences between the two groups in weight, height, body mass index, follicle stimulating hormone, luteinizing hormone, estradiol, total testosterone, prolactin, thyrotropin.

Table 2 compares the parameters of the seminogram in the two study groups.

Table 1: Clinical characteristics and hormonal profile upon admission to the clinic of andrology.

\begin{tabular}{|l|l|l|l|}
\hline Characteristics & Group 1 N=46 MeantSD & Group 2 N=272 Mean \pm SD & P value \\
\hline Age $($ years) & $36.0 \pm 5.3$ & $37.3 \pm 6.8$ & 0.22 \\
\hline Weight $(\mathrm{kg})$ & $80.8 \pm 13.2$ & $78.8 \pm 12.8$ & 0.32 \\
\hline Height $(\mathrm{cm})$ & $169 \pm .07$ & $168 \pm .06$ & 0.91 \\
\hline Body mass index $\left(\mathrm{kg} / \mathrm{m}^{2}\right)$ & $28.3 \pm 4.4$ & $27.6 \pm 4.3$ & 0.32 \\
\hline Follicle stimulating hormone $(\mathrm{mUI} / \mathrm{ml})$ & $3.7 \pm 2.8$ & $4.0 \pm 3.1$ & 0.53 \\
\hline Luteinizing hormone $(\mathrm{mUI} / \mathrm{ml})$ & $2.9 \pm 1.3$ & $2.9 \pm 1.3$ & 0.89 \\
\hline Estradiol $(\mathrm{pg} / \mathrm{ml})$ & $41.4 \pm 15.7$ & $40.2 \pm 13.4$ & 0.59 \\
\hline Total Testosterone $(\mathrm{nmol} / \mathrm{L})$ & $13.3 \pm 5.3$ & $12.9 \pm 7.3$ & 0.76 \\
\hline Prolactin $(\mathrm{ng} / \mathrm{ml})$ & $10 \pm 5.8$ & $9.3 \pm 5.1$ & 0.41 \\
\hline Thyrotropin $(\mathrm{mUI} / \mathrm{ml})$ & $2.8 \pm 2.0$ & $2.9 \pm 1.1$ & 0.49 \\
\hline
\end{tabular}

SD:Standard Deviation

Table 2: Spermatobioscopy in both groups of males with infertility.

\begin{tabular}{|l|l|l|l|}
\hline Parameters of spermatobioscopy & Group $1 \mathrm{~N}=46$ Mean \pm SD & Group 2 N=272 Mean \pm SD & Palue \\
\hline Sperm concentration $\left(10^{6} / \mathrm{ml}\right)$ & $47.5 \pm 38.1$ & $64.3 \pm 41.2$ & 0.09 \\
\hline Morphology (normal forms \%) & $2.0 \pm 1.8$ & $2.1 \pm 1.5$ & 0.59 \\
\hline Progressive mobility $(\mathrm{A}+\mathrm{B} \%)$ & $38.7 \pm 23.8$ & $50.1 \pm 18.9$ & 0.03 \\
\hline Hypo-osmotic test $(\%$ normal) & $56.4 \pm 16.9$ & $59.3 \pm 22.9$ & 0.40 \\
\hline Leukocytes $\left(10^{6} / \mathrm{ml}\right)$ & $1.1 \pm 1.6$ & $1.8 \pm 2.9$ & 0.13 \\
\hline
\end{tabular}

SD:Standard Deviation 
Table 3: Risk factors related to the presence of anti-sperm antibodies.

\begin{tabular}{|l|l|l|l|l|}
\hline Risk factors & Group $1 \mathrm{~N}=46(\%)$ & Group 2 N=272(\%) & OR (95\% CI) & P value \\
\hline Testicular trauma & $7(12.3)$ & $50(87.7)$ & $0.80(0.38-1.71)$ & 0.570 \\
\hline Testicular neoplasia & $1(25.0)$ & $4(75.0)$ & $1.71(0.30-9.57)$ & 0.550 \\
\hline Varicocele & $22(23.7)$ & $71(76.3)$ & $2.14(1.27-3.61)$ & 0.004 \\
\hline Scrotal surgery & $4(8.3)$ & $44(91.7)$ & $0.52(0.19-1.40)$ & 0.170 \\
\hline Retractile testicle & $14(26.4)$ & $39(73.6)$ & $2.13(1.23-3.70)$ & 0.008 \\
\hline infection & $8(12.1)$ & $58(87.9)$ & $0.78(0.38-1.60)$ & 0.500 \\
\hline
\end{tabular}

There was a significant decrease in progressive mobility in group $1(38.7 \pm 23.8)$ vs group $2(50.1 \pm 18.9) \mathrm{p}=0.03$, however, these values are within the lower limit of normal according to the WHO parameters 2010.

No significant correlation was observed between antisperm antibodies and other parameters of ejaculation such as concentration, ( $p$ 0.09) morphology (p 0.59) and the hypoosmotic test ( $\mathrm{p} 0.40$ ), did not show significant difference in both men with positive antibodies as negative.

The concentrations of leukocytes in the semen of males with infertility are elevated in both groups without

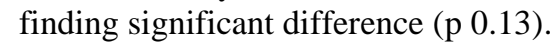

Subsequently, the risk factors associated with the presence of anti-sperm antibodies were analyzed (Table 3 ), finding the risk of varicocele $23.7 \%$, OR 2.14 (1.273.61) $\mathrm{p}=0.004$ and the retractable testicle $26.4 \%$, OR as significant risk. $2.13(1.23-3.70) \quad \mathrm{p}=0.008$, unlike testicular trauma $12.3 \%$ OR $0.80(0.38-1.71) \mathrm{p}=0.57$, testicular neoplasia $25 \%$ OR $1.71(0.30-9.57) \mathrm{p}=0.55$, scrotal surgery $8.3 \%$ OR $0.52 \quad(0.19-1.40) \quad \mathrm{p}=0.17$, infection $12.1 \%$ OR $0.78(0.38-1.60) \mathrm{p}=0.50$ in which no significant difference was found.

\section{DISCUSSION}

The prevalence of infertile men with positive anti-sperm antibodies was $14.5 \%$, similar to that reported in the literature of couples with positive anti-sperm antibodies with a prevalence ranging from 8.1 to $30.3 \%$, however, their presence has been reported also in fertile couples in a 1.2 to $19 \% .^{2,11-14}$ Leushuis $\mathrm{E}$ et al, in his work that included 1794 infertile marriages, a positive anti-sperm antibody test was detected in 3\% and Garcia PC et al, in $18.1 \% .^{4,15}$ Using lower cut-off points, a small difference in the detection rate of anti-sperm antibodies could appear, however its clinical effects on patients' fertility status would probably be negligible. ${ }^{16}$

Endocrine disruptors and seminal infection that interfere with the synthesis, storage, release, transport of sperm responsible for the regulation of homeostasis and the process of development can lead to compromised fertility. ${ }^{4}$ However, in present study, endocrinological characteristics were compared somatometric and infectious of both groups without finding significant difference between the groups in any of the characteristics achieving with this, 2 homogeneous groups to compare the alterations in spermatobioscopy.

In this study, it was shown that in men who are infertile with positive anti-sperm antibodies, progressive mobility $(<p \quad 0.03)$ is significantly reduced, suggestive of damage to the sperm membrane, as reported by Veron $G$ et al, 2016 in your studio. ${ }^{6}$

Rossato et al, showed recently that the score of the Hypoosmotica test in the sperm sample of patients with autoimmune infertility was significantly lower than that observed in the spermatozoa of normozoospermic subjects negative for anti-sperm antibodies. ${ }^{5}$ In present work, no significant difference was found in the hypoosmotic test ( $\mathrm{p} \mathrm{0.40)}$ concluding that no damage was found to the spermatic membrane with this test.

In the work of Garcia P et al, studying a Latin American population, it was observed that a higher proportion of motile sperm do not have progressive movement but this finding was not significantly associated with anti-sperm antibodies, but found a correlation between positive antisperm antibodies and increase of white blood cells in semen as well as decrease of the hypoosmotic test. ${ }^{4}$ Unlike the present work in which the white blood cells in semen and the Hypo- osmotic test did not show the same correlation.

Any damage to the blood-testicular barrier should be suspected as a risk factor for the development of antisperm antibodies, including the increase in temperature and scrotal infections, as described by Yumei $\mathrm{J}$ et al in their meta-analysis the rate of positive anti-sperm antibodies was higher in patients with chronic prostatitis OR 3.26 (1.86-5.71) than in healthy individuals. ${ }^{3,5}$ In present study, this result was not replicated since authors found an OR $0.78(0.38-1.60)$ for prostatitis similar to that observed by Marconi, $M$ et al, with non-significant levels of anti-sperm antibodies in patients with chronic epididymitis and orchitis. ${ }^{16}$

It has been shown that immune infertility is found in $15 \%$ of patients with varicocele, it is suggested that positive anti-sperm antibodies prior to varicocelectomy is an unfavorable prognostic factor for sperm after 
varicocelectomy because it worsens prognosis. recovery to fertility after varicocelectomy. ${ }^{5}$ In this study, $22 \%$ of male infertile men positive for anti-sperm antibodies had varicocele, this being a significant risk factor, OR 2.14 (1.27-3.61) $\mathrm{p}=0.004$ and scrotal surgery $8.3 \%$ OR 0.52 (0.19-1.40) $\mathrm{p}=0.17$ without being significantly risky. Varicocelectomy can lead to improved sperm count and morphology, but motility is affected when it is accompanied by positive anti-sperm antibodies similar to that found in this work. ${ }^{5,17}$

In the work of Sinisi A et al, authors report an increase in the prevalence of anti-sperm antibodies of $28 \%$ in men with a history of cryptorchidism treated or not treated with orchidopexy. In present study, it was found in $26.4 \%$ of infertile men with positive anti-sperm antibodies and retractable testicles with an OR $2.13(1.23-3.70) \mathrm{P}=0.008$, however in the population studied by Sinasi A, it included a prepuber population and there is a high possibility that an indefinite percentage of patients underwent orchidopexy and this is the cause of the appearance of antisperm antibodies. ${ }^{18,19}$ In the population studied by Jiang $\mathrm{H}$ et al, authors reviewed a history of 48 men with cryptorchidism who underwent orchidopexy at the prepubertal age, finding $6.7 \%$ with antisperm antibodies, without being greater than 50\%. Therefore, they could not demonstrate a significant level of antisperm antibodies in infertile men with a history of cryptorchidism. ${ }^{20}$

In present study, a prevalence of $14.5 \%$ males with positive anti-sperm antibodies was observed, the condition of sperm motility was confirmed, and the varicocele and retractable testicle were observed as the main associated risk factor. Among the limitations of the study was not a group of fertile men with anti-sperm antibodies with which the seminal alterations could be compared, the study does not assess the real role of antisperm antibodies in human fertility, in the following Investigations will be able to compare the presence of anti-sperm antibodies and the fertilization rate with different reproduction techniques.

\section{CONCLUSION}

The main risk factors associated with the presence of anti-sperm antibodies are varicocele and retractable testis. Presenting in $14.5 \%$ of males with infertility in which sperm motility is affected in the semen.

\section{Funding: National Institute of Perinatology}

Conflict of interest: None declared

Ethical approval: The study was approved by the Ethics and Local Research Committee of the National Institute of Perinatology

\section{REFERENCES}

1. Zhao Y, Zhao E, Zhang C, Zhang H. Study of the changes of acrosomal enzyme, nitric oxide synthase, and superoxide dismutase of infertile patients with positive antisperm antibody in seminal plasma. Cell Biochem Biophys. 2015;73(3):639-42.

2. Vazquez-Levin MH, Marín-Briggiler CI, Veaute C. Antisperm antibodies: invaluable tools toward the identification of sperm proteins involved in fertilization. Am J Reprod Immunol. 2014;72(2):206-18.

3. Jiang Y, Cui D, Du Y, Lu J, Yang L, Li J, et al. Association of anti-sperm antibodies with chronic prostatitis: a systematic review and meta-analysis. J Reprod Immunol. 2016;118:85-91.

4. Garcia PC, Rubio EM, Pereira OC. Antisperm antibodies in infertile men and their correlation with seminal parameters. Reprod Med Biol. 2007;6(1):338.

5. Rossato M, Galeazzi C, Ferigo M, Foresta C. Antisperm antibodies modify plasma membrane functional integrity and inhibit osmosensitive calcium influx in human sperm. Hum Reprod. 2004;19(8):1816-20.

6. Verón GL, Molina RI, Tissera AD, Estofan GM, Marín-Briggiler CI, Vazquez-Levin MH. Incidence of sperm surface autoantibodies and relationship with routine semen parameters and sperm kinematics. Am J Reprod Immunol. 2016;76(1):59-69.

7. Cui D, Han G, Shang Y, Liu C, Xia L, Li L, et al. Antisperm antibodies in infertile men and their effect on semen parameters: a systematic review and metaanalysis. Clinica Chimica Acta. 2015;444:29-36.

8. Cooper TG, Noonan E, Von Eckardstein S, Auger J, Baker HW, Behre HM, et al. World Health Organization reference values for human semen characteristics. Hum Reprod Update. 2010;16(3):231-45.

9. Flickinger CJ, Howards SS, Bush LA, Baker LA, Herr JC. Temporal recognition of sperm autoantigens by $\mathrm{IgM}$ and $\mathrm{IgG}$ autoantibodies after vasectomy and vasovasostomy. J Reprod Immunol. 1994;27(2):13550 .

10. Abshagen K, Behre HM, Cooper TG, Nieschlag E. Influence of sperm surface antibodies on spontaneous pregnancy rates. Fertil Steril. 1998;70(2):355-6.

11. Francavilla F, Barbonetti A. Male autoimmune infertility. In Immune Infertility. 2017:187-96. Springer, Cham.

12. Lähteenmäki A, Reima I, Hovatta O. Treatment of severe male immunological infertility by intracytoplasmic sperm injection. Hum Reprod. 1995;10(11):2824-8.

13. Check JH, Aly J. Sperm antibodies and assisted reproduction. In Immune Infertility. 2017:223-34. Springer, Cham.

14. Collins JA, Burrows EA, Yeo J, YoungLai EV. Frequency and predictive value of antisperm antibodies among infertile couples. Hum Reprod. 1993;8(4):592-8.

15. Leushuis E, van der Steeg JW, Steures P, Repping S, Schöls W, van der Veen F, et al. Immunoglobulin G 
antisperm antibodies and prediction of spontaneous pregnancy. Fertil Steril. 2009;92(5):1659-65.

16. Marconi M, Nowotny A, Pantke P, Diemer T, Weidner W. Antisperm antibodies detected by mixed agglutination reaction and immunobead test are not associated with chronic inflammation and infection of the seminal tract. Andrologia. 2008;40(4):227-34.

17. Bonyadi MR, Madaen SK, Saghafi M. Effects of varicocelectomy on anti-sperm antibody in patients with varicocele. J Reprod Infertil. 2013;14(2):73-8.

18. Sinisi AA, Pasquali D, Papparella A, Valente A, Orio F, Esposito D, et al. Antisperm antibodies in cryptorchidism before and after surgery. J Urol. 1998;160(5):1834-7.

19. Marconi M, Weidner W. Site and risk factors of antisperm antibodies production in the male population. In Immune Infertility. 2017:133-47. Springer, Cham.

20. Jiang H, Zhu WJ. Cryptorchidism is not a risk factor for antisperm antibody production in postorchidopexy males with infertility. Urol Int. 2013;90(4):470-4.

Cite this article as: Cardeña IA, Rodríguez ACA, Treviño EOR, Navarro JJA, Muñoz ER, Sánchez AR, et al. Prevalence of anti-sperm antibodies, risk factors associated and their impact on spermatobioscopy in infertile men. Int J Reprod Contracept Obstet Gynecol 2019;8:1240-5. 